Research Article

\title{
Simultaneous Determination of Caffeine and Taurine in Energy Drinks by FT-MIR Spectroscopy Coupled with Multivariate Analysis
}

\author{
Marcela González-Vázquez, ${ }^{1}$ Ofelia Gabriela Meza-Márquez ${ }^{\mathbb{D}},{ }^{1}$ \\ Tzayhri Gallardo-Velázquez, ${ }^{2}$ Guillermo Osorio-Revilla, ${ }^{1}$ José Luis Velázquez Hernández, ${ }^{3}$ \\ and Maylet Hernández-Martínez \\ ${ }^{1}$ Instituto Politécnico Nacional, Escuela Nacional de Ciencias Biológicas-Zacatenco, Departamento de Ingeniería Bioquímica, \\ Av. Wilfrido Massieu S/N,Esq. Cda. Miguel Stampa. Col. Unidad Profesional Adolfo López Mateos,Zacatenco. Alcaldía Gustavo \\ A. Madero, Ciudad de México, C.P. 07738, Mexico \\ ${ }^{2}$ Instituto Politécnico Nacional, Escuela Nacional de Ciencias Biológicas-Santo Tomás, Departamento de Biofísica, \\ Prolongación de Carpio y Plan de Ayala S/N. Col. Santo Tomás. Alcaldía Miguel Hidalgo, Ciudad de México, C.P. 07738, Mexico \\ ${ }^{3}$ Independent Advisor in the Food Industry, Ciudad de México, C.P. 07738, Mexico
}

Correspondence should be addressed to Ofelia Gabriela Meza-Márquez; ogmmz@yahoo.com.mx

Received 25 August 2020; Revised 25 November 2020; Accepted 28 November 2020; Published 10 December 2020

Academic Editor: Jose S. Camara

Copyright @ 2020 Marcela González-Vázquez et al. This is an open access article distributed under the Creative Commons Attribution License, which permits unrestricted use, distribution, and reproduction in any medium, provided the original work is properly cited.

\begin{abstract}
Energy drinks have been studied due to their damaging side effects on the health of their consumers when consumed in excess or when combined with alcohol. Our objective was to develop chemometric models, based on Fourier-transform mid-infrared (FTMIR) spectroscopy, to quantify the taurine and caffeine content in energy drinks rapidly and simultaneously. The taurine and caffeine content in the 50 samples ranged between 0 and $69.51 \mathrm{mg} / 100 \mathrm{~mL}$ and 14.92 and $1126.17 \mathrm{mg} / 100 \mathrm{~mL}$, respectively. The best prediction model was obtained with the partial least squares (PLS1) algorithm; for taurine, the following values were obtained: determination coefficient of calibration $\left(R c^{2}\right)=0.9999$, standard error of calibration $($ SEC) $=0.15$, determination coefficient of validation $\left(R v^{2}\right)=0.9997$, and standard error of prediction (SEP) $=0.16$; for caffeine, $R c^{2}=0.9999, \mathrm{SEC}=0.26, R v^{2}=0.9999$, and $\mathrm{SEP}=0.32$. The model developed with PLS1 showed certainty in predictions during the validation stage and during application to external samples. FT-MIR coupled to chemometrics is a reliable and fast technique (compared to conventional techniques) to quantify taurine and caffeine in energy drinks simultaneously.
\end{abstract}

\section{Introduction}

Energy drinks usually contain carbohydrates, vitamins, minerals, and taurine and caffeine in higher amounts. There is no official international legislation that establishes the maximum allowed limit (MAL) for taurine in these drinks, although there is a recommendation of $40 \mathrm{mg}$ of acceptable daily intake (ADI) $[1,2]$. The Mexican regulation [3] indicates that the MAL for caffeine in energy drinks must be of $20 \mathrm{mg} / 100 \mathrm{~mL}$; likewise, the same norm indicates that the ADI for caffeine cannot exceed $165 \mathrm{mg}$.
Excessive or inadequate consumption (for example, combined with alcohol) of energy drinks has become a public health concern. With the increase in their consumption, the ADI of the main ingredients (taurine and caffeine) found in the energy drinks could easily exceed and increase the noxious side effects in consumers, such as increase in blood pressure, hypoglycemia, dizziness, diarrhea, peptic ulcer, arrhythmias, dehydration, and cerebral and nervous system damage [4].

In some energy drinks, the labels of the product do not provide detailed information on the ingredients or do not 
indicate the amount at which the main ingredients (taurine and caffeine) are contained. Therefore, the need arises to count upon analysis methods that will allow verifying and controlling the taurine and caffeine concentrations in energy drinks. Many analytical methods have been developed to quantify taurine and caffeine contents in energy drinks. To quantify taurine, micellar electrokinetic chromatography (MEKC) [5], capillary electrophoresis, UV-Vis spectroscopy [6], nuclear magnetic resonance (NMR) [7], and highperformance liquid chromatography (HPLC) with different detectors $[8,9]$ have been used. To quantify caffeine, different techniques have been used: HPLC [10], gas chromatography (GC), thin layer chromatography, UV-Vis spectroscopy, and NMR [5].

The mentioned techniques have been efficacious to determine taurine and caffeine in energy drinks; however, all these techniques require a complex pretreatment before the analysis, are time-consuming and laborious, and use large amounts of reagents and solvents (noxious for the analyst and the environment). Fourier-transform mid-infrared (FTMIR) spectroscopy is a very useful technique to determine chemical components in foods, as it is fast, samples need minimal or nil pretreatment, and it does not produce toxic wastes. Although UV-Vis spectroscopy also has the aforementioned advantages, this technique is considered univariate, unlike FT-MIR spectroscopy, which is multivariate when coupled to chemometrics. Therefore, FT-MIR spectroscopy is an alternative to conventional methods because, coupled to multivariate analysis, it allows developing prediction models that will enable to know quantitatively the composition of the sample without performing pretreatments and without the use of solvents and reagents [11]. FTMIR spectroscopy has been used to quantify taurine in energy drinks [12]; however, it has not been used to quantify caffeine in this type of drinks; in addition, FT-MIR spectroscopy together with multivariate analysis has not been used to quantify taurine and caffeine simultaneously. Therefore, this study represents, to the best of our knowledge, the first study aimed at solving this issue.

The objective of this work was to develop chemometric models based on FT-MIR spectroscopy to quantify taurine and caffeine simultaneously in energy drinks aiming to develop a simple, fast, and reliable methodology.

\section{Materials and Methods}

2.1. Samples. Fifty samples of energy drinks of different brands were selected randomly and acquired from different supermarkets and convenience stores in Mexico City, Mexico. All samples were stored at room temperature $\left( \pm 20^{\circ} \mathrm{C}\right)$ until their analyses.

2.2. Determination of Taurine. Taurine was quantified in triplicate by the technique described by Lau et al. [13]. The calibration curve was prepared with a stock solution of $400 \mathrm{mg} / \mathrm{L}$ of taurine (Sigma Chemical, St. Louis, MO, USA), and this solution was used to obtain the calibration standards with concentrations of $6,25,50,100,200$, and $400 \mathrm{mg}$ /
L. In each standard solution, the absorbance was determined at $630 \mathrm{~nm}$ (spectrophotometer Jenway, model 7305, Staffordshire, UK), with distilled water as the blank. To analyze the samples (previously degassed), a $2 \mathrm{~mL}$ aliquot was taken and placed in a precipitation flask together with $4 \mathrm{~g}$ of ionic exchange resin. The mixture was agitated for $15 \mathrm{~min}$ and filtered (Whatman 40). The filtrate was gauged to $10 \mathrm{~mL}$ with distilled water. Then, $2 \mathrm{~mL}$ of the filtrate was supplemented with $2 \mathrm{~mL}$ of phosphate buffer, $2 \mathrm{~mL}$ of phenol, and $2 \mathrm{~mL}$ of sodium hypochlorite and gauged to $10 \mathrm{~mL}$ with distilled water. Afterwards, the solution was mixed and left to rest for $30 \mathrm{~min}$. The absorbance was read at $630 \mathrm{~nm}$ against a blank of the buffering phosphate, phenol, and sodium hypochlorite solution. Results were expressed in milligrams per $100 \mathrm{~mL}$ $(\mathrm{mg} / 100 \mathrm{~mL})$.

2.3. Determination of Caffeine. Caffeine was quantified in triplicate following the technique described by Jenway [14]. The calibration curve was constructed with a stock solution of $100 \mathrm{mg} / \mathrm{L}$ of caffeine (Sigma Chemical, St. Louis, MO), and this solution was used to obtain calibration standards with concentrations of $5,10,20,30,40,50$, and $80 \mathrm{mg} / \mathrm{L}$. The absorbance was determined in each standard solution at $260 \mathrm{~nm}$ (Jenway spectrophotometer, model 7305, Staffordshire, UK) with distilled water as the blank. $50 \mathrm{~mL}$ of the degassed sample was supplemented with $25 \mathrm{~mL}$ chloroform in a separation funnel. The funnel was inverted three times, ventilating it after each inversion. Afterwards, the chloroform layer was removed, and the extraction procedure was repeated twice. Finally, the absorbance was read at $260 \mathrm{~nm}$ against a chloroform blank. Results were expressed in milligrams per $100 \mathrm{~mL}(\mathrm{mg} / 100 \mathrm{~mL})$.

2.4. Statistical Analysis. All results were analyzed through one-way ANOVA and Tukey's multiple comparisons of means $(p \leq 0.05)$. Statistical analyses were performed with Minitab version 16.1.0 software (State College, PA, USA).

2.5. FT-MIR Spectra. FT-MIR spectra were recorded in a Fourier-transform infrared spectrophotometer (FTIR) (model GX, PerkinElmer ${ }^{\circledR}$, Massachusetts, USA), with attenuated total reflectance (ATR) and zinc selenide crystal (ZnSe) (model 022-12xx, PerkinElmer ${ }^{\circledR}$, Massachusetts, USA). To obtain the data, Spectrum version 5.3.1 software was used (PerkinElmer ${ }^{\circledR}$, Massachusetts, USA).

FT-MIR spectra were obtained in the mid-infrared region $\left(4000-550 \mathrm{~cm}^{-1}\right)$ with 64 scans at a resolution of $4 \mathrm{~cm}^{-1}$, in absorbance units (A). Before obtaining the FTMIR spectra of the samples, the reference spectrum against air was determined to eliminate the spectral contribution of the environment. This was achieved by reading the empty ATR crystal under the same instrumental conditions of the sample, and the result was taken as the reference blank. The FT-MIR spectra were obtained with $1 \mathrm{~mL}$ of each sample (previously degassed) on the $\mathrm{ZnSe}$ crystal. Readings of samples were performed in triplicate, and then they were averaged with Spectrum version 5.3.1 software 
(PerkinElmer ${ }^{\circledR}$, Massachusetts, USA). After ending each determination, the $\mathrm{ZnSe}$ crystal was carefully washed with a liquid detergent, rinsed with distilled water, cleaned with disposable wipes, and left to dry in the environment.

2.6. Multivariate Analysis. The multivariate analysis was performed with Spectrum Quant+ version 4.51.02 software (PerkinElmer ${ }^{\circledR}$, Massachusetts, USA), which includes the principal component regression (PCR) algorithm and the partial least squares (PLS1 and PLS2). The regression model was built with 50 average FT-MIR spectra. Forty average FTMIR spectra were used to calibrate the model and 10 average FT-MIR spectra to validate the model.

The spectra pretreatments to improve the predictive ability of the model included smoothing using the Savitzky-Golay algorithm with 19 points to eliminate the random noise present in the signal and to increase the signal/noise relation, the baseline correction (offset) to correct changes in the baseline deviation, second derivative with 13 points to increase spectral differences, and normalization using multiplicative correction of scattered light (MSC) to reduce multicolinearity and the effects of the baseline shift and curvature on spectra arising from scattering effects due to physical effects.

The model with the best calibration was selected based on (1) factors or latent variables, (2) coefficient of determination of calibration $\left(R c^{2}\right)$, and (3) standard error of calibration (SEC) [15].

The predictive ability of the model was evaluated with (1) coefficient of validation $\left(R v^{2}\right)$, (2) standard error of prediction (SEP), (3) Mahalanobis distance (MD), (4) residual ratio (RR), (5) residual error (RE), (6) ratio of performance to deviation (RPD), and finally, (7) relative difference percentage $(\% \mathrm{RD})$ which was calculated with the following equation:

$$
\% \mathrm{RD}=\frac{\text { actual value }- \text { predicted value }}{\text { actual value }} \times 100 .
$$

2.7. Application of the Model. The model was applied to five energy drinks different from those used in the calibration and validation stages. Application of the model is relevant to evaluate the prediction of unknown samples, and this stage is used as another evidence to verify the predictive ability of the model.

\section{Results and Discussion}

3.1. Taurine Concentration. The taurine content of energy drinks varied from 0 to $69.51 \mathrm{mg} / 100 \mathrm{~mL}$ (Table 1). ANOVA analysis revealed a significant difference among samples $(p \leq 0.05)$. The taurine content reported in the label of the product is very similar to that found in this work. However, $62 \%$ of energy drinks had no label information on their taurine content. In $10 \%$ of samples (drinks 1, 13, 24, 26, and 36 ), no taurine was detected. The literature reports the taurine concentration in energy drinks from nondetected
(ND) to $315.3 \mathrm{mg} / 100 \mathrm{~mL}[5,7-9]$. The taurine content found in this work agreed with that reported in the literature.

It is recommended worldwide that the ADI for taurine should be $40 \mathrm{mg}[1,2]$. Of the analyzed energy drinks, $99 \%$ (49 energy drinks) were below the ADI for taurine. Energy drink No. 2 exceeded the recommendation as it contained $69.51 \mathrm{mg} / 100 \mathrm{~mL}$ of taurine. There is no official international legislation that establishes the MAL for taurine in energy drinks. Because of this, the manufacturer is not bound to include information on the amount of this amino acid in its product. However, it is essential to know the impact of the ingredients of energy drinks and, according to the risks, to implement regulating measurements to avoid negative consequences to the consumer.

3.2. Caffeine Concentration. The caffeine content in energy drinks varied significantly $(p \leq 0.05)$, from 14.92 to $1126.17 \mathrm{mg} / 100 \mathrm{~mL}$ (Table 1 ). Of the analyzed energy drinks, 94\% (47 samples) exceeded the MAL for caffeine established in NOM-218-SSA1-2011, and only 6\% (3 samples) (drinks 18, 26, and 32) complied with NOM-218-SSA1-2011 [3].

Energy drink No. 30 presented the highest caffeine concentration $(1126.17 \mathrm{mg} / 100 \mathrm{~mL})$. The reason for this high concentration is that among its ingredients, aside from caffeine, are guarana extracts, and this fruit is rich in caffeine, as it has 4 times more caffeine than coffee beans, aside from having other methylxanthines such as theobromine and theophylline [16].

The caffeine content reported on the product's label is different from that quantified in this research; for example, the label of energy drink No. 8 reports a caffeine concentration of $19.5 \mathrm{mg} / 100 \mathrm{~mL}$, and the chemical analysis quantified $27.42 \mathrm{mg} / 100 \mathrm{~mL}$. In addition, on some labels, the caffeine content was not reported.

The literature reports caffeine concentrations in energy drinks from nondetected to $2500 \mathrm{mg} / 100 \mathrm{~mL}[5,10]$. The caffeine content obtained in this work varies with respect to other studies; this could be due to the lack of legislation. For example, the European Union (EU) has not established the MAL of caffeine in energy drinks; it has only indicated that if the product contains more than $150 \mathrm{mg} / \mathrm{L}$ of caffeine, the product must be labelled as "high caffeine content," and this legend must be placed together with the name of the product. Likewise, the EU establishes that the label of the product must clearly indicate the caffeine content per $100 \mathrm{~mL}$ [17]; however, energy drinks that do not comply with this regulation are marketed freely.

Results indicate that the main energizing ingredient of these drinks is caffeine, as this compound was quantified in all drinks, whereas taurine was only quantified in some of them, for example, in drink No. 26, no taurine was quantified; however, it presents "high caffeine content" $(656.8 \mathrm{mg} / 100 \mathrm{~mL})$.

It is important to control the amount of energizing ingredients (taurine and caffeine) in energy drinks because their consumption has increased in the population with the promise of keeping them alert and active for longer time spans. The World Health Organization (WHO) has pointed 
TABle 1: Taurine and caffeine concentrations in energy drinks.

\begin{tabular}{|c|c|c|c|c|}
\hline Energy drink & Taurine (mg 100/mL) & Reported on the label $(\mathrm{mg} / 100 \mathrm{~mL})$ & Caffeine (mg 100/mL) & Reported on the label (mg 100/mL) \\
\hline 1 & $\mathrm{ND}^{s}$ & WI & $81.29 \pm 0.6^{x}$ & 32 \\
\hline 2 & $69.51 \pm 1.4^{\mathrm{a}}$ & WI & $206.26 \pm 2.0^{\mathrm{r}}$ & WI \\
\hline 3 & $24.34 \pm 1.4^{\mathrm{bc}}$ & WI & $223.27 \pm 1.1^{\mathrm{q}}$ & WI \\
\hline 4 & $27.04 \pm 1.2^{\mathrm{b}}$ & WI & $236.40 \pm 1.6^{\mathrm{p}}$ & WI \\
\hline 5 & $1.88 \pm 0.4^{\mathrm{qrs}}$ & 1.45 & $231.68 \pm 0.2^{\mathrm{p}}$ & WI \\
\hline 6 & $4.95 \pm 0.2^{\mathrm{k}-\mathrm{r}}$ & 4.16 & $34.15 \pm 0.6^{\mathrm{a}-\mathrm{b}}$ & 80 \\
\hline 7 & $4.95 \pm 0.2^{\mathrm{k}-\mathrm{r}}$ & 5.82 & $79.09 \pm 0.7^{\mathrm{x}}$ & 80 \\
\hline 8 & $2.74 \pm 0.4^{\mathrm{o}-\mathrm{s}}$ & 3.09 & $27.42 \pm 1.1^{\mathrm{ac} \text { ad }}$ & 19.5 \\
\hline 9 & $12.31 \pm 0.8^{\mathrm{d}-\mathrm{g}}$ & WI & $102.61 \pm 1.3^{\mathrm{v}}$ & WI \\
\hline 10 & $2.54 \pm 1.2^{\mathrm{p}-\mathrm{s}}$ & 2.61 & $57.20 \pm 1.8^{\mathrm{z}}$ & WI \\
\hline 11 & $6.03 \pm 1.1^{\mathrm{j}-\mathrm{q}}$ & 7.82 & $88.27 \pm 1.0^{\mathrm{w}}$ & WI \\
\hline 12 & $10.28 \pm 0.7^{\mathrm{e}-\mathrm{i}}$ & WI & $63.57 \pm 0.6^{y}$ & WI \\
\hline 13 & $\mathrm{ND}^{\mathrm{s}}$ & WI & $386.38 \pm 0.3^{1}$ & WI \\
\hline 14 & $12.52 \pm 0.6^{\mathrm{d}-\mathrm{f}}$ & WI & $101.33 \pm 0.3^{\mathrm{v}}$ & WI \\
\hline 15 & $4.08 \pm 1.6^{\mathrm{m}-\mathrm{s}}$ & 4.25 & $903.47 \pm 0.3^{\mathrm{c}}$ & WI \\
\hline 16 & $1.03 \pm 0.07^{\mathrm{r}-\mathrm{s}}$ & WI & $36.77 \pm 0.7^{\mathrm{a}-\mathrm{b}}$ & 30 \\
\hline 17 & $1.03 \pm 0.13^{\mathrm{r}-\mathrm{s}}$ & WI & $37.03 \pm 0.8^{\mathrm{a}-\mathrm{b}}$ & 30 \\
\hline 18 & $1.03 \pm 0.07^{\mathrm{r}-\mathrm{s}}$ & WI & $14.92 \pm 0.5^{\mathrm{ae}}$ & 15 \\
\hline 19 & $22.60 \pm 0.04^{\mathrm{c}}$ & WI & $556.28 \pm 1.2^{\mathrm{i}}$ & WI \\
\hline 20 & $8.85 \pm 1.7^{\mathrm{f}-\mathrm{k}}$ & 8.42 & $285.12 \pm 1.6^{\mathrm{n}}$ & WI \\
\hline 21 & $10.48 \pm 0.4^{\mathrm{e}-\mathrm{i}}$ & WI & $118.77 \pm 1.0^{\mathrm{t}}$ & WI \\
\hline 22 & $9.40 \pm 0.9^{\mathrm{e}-\mathrm{j}}$ & 10.74 & $32.31 \pm 1.1^{\mathrm{ab} \mathrm{ac}}$ & 19.5 \\
\hline 23 & $8.41 \pm 1.3^{\mathrm{f}-1}$ & 9.26 & $26.66 \pm 0.7^{\mathrm{ad}}$ & 19.5 \\
\hline 24 & $\mathrm{ND}^{\mathrm{s}}$ & WI & $51.35 \pm 0.4^{\mathrm{aa}}$ & WI \\
\hline 25 & $1.05 \pm 0.04^{\mathrm{r}-\mathrm{s}}$ & 1.42 & $15.24 \pm 0.8^{\mathrm{ae}}$ & WI \\
\hline 26 & $\mathrm{ND}^{\mathrm{s}}$ & WI & $656.80 \pm 1.9^{\mathrm{h}}$ & WI \\
\hline 27 & $3.64 \pm 0.06^{\mathrm{n}-\mathrm{s}}$ & 3.72 & $870.50 \pm 0.6^{\mathrm{d}}$ & WI \\
\hline 28 & $13.20 \pm 1.1^{\mathrm{d}-\mathrm{e}}$ & WI & $806.70 \pm 0.6^{\mathrm{e}}$ & WI \\
\hline 29 & $2.38 \pm 0.2^{\mathrm{p}-\mathrm{s}}$ & 3.72 & $764.21 \pm 0.8^{\mathrm{f}}$ & WI \\
\hline 30 & $8.04 \pm 0.4^{\mathrm{h}-\mathrm{m}}$ & 7.43 & $1126.17 \pm 5.0^{\mathrm{a}}$ & WI \\
\hline 31 & $7.85 \pm 0.4^{\mathrm{h}-\mathrm{n}}$ & 7.89 & $766.01 \pm 0.4^{\mathrm{f}}$ & WI \\
\hline 32 & $26.60 \pm 4.3^{\mathrm{b}-\mathrm{c}}$ & WI & $16.49 \pm 0.1^{\text {ae }}$ & 15 \\
\hline 33 & $11.37 \pm 0.5^{\mathrm{d}-\mathrm{h}}$ & WI & $979.02 \pm 5.6^{\mathrm{b}}$ & WI \\
\hline 34 & $7.37 \pm 0.8^{\mathrm{h}-\mathrm{n}}$ & 7.23 & $692.89 \pm 0.5^{\mathrm{g}}$ & WI \\
\hline 35 & $6.43 \pm 0.8^{i-p}$ & 5.41 & $171.88 \pm 0.04^{\mathrm{s}}$ & WI \\
\hline 36 & $\mathrm{ND}^{\mathrm{s}}$ & WI & $63.55 \pm 0.5^{y}$ & WI \\
\hline 37 & $6.82 \pm 0.5^{\mathrm{i}-\mathrm{o}}$ & 5.43 & $49.69 \pm 1.5^{\text {aa }}$ & WI \\
\hline 38 & $12.29 \pm 0.9^{\mathrm{d}-\mathrm{g}}$ & WI & $34.15 \pm 0.5^{\mathrm{ab}}$ & WI \\
\hline 39 & $10.57 \pm 1.9^{\mathrm{e}-\mathrm{i}}$ & WI & $32.30 \pm 0.7^{\mathrm{ab} \mathrm{ac}}$ & WI \\
\hline 40 & $7.01 \pm 1.9^{\mathrm{i}-\mathrm{n}}$ & WI & $50.34 \pm 1.1^{\mathrm{aa}}$ & WI \\
\hline 41 & $9.50 \pm 1.6^{\mathrm{e}-\mathrm{j}}$ & WI & $66.59 \pm 1.4^{\mathrm{y}}$ & WI \\
\hline 42 & $7.55 \pm 0.9^{\mathrm{h}-\mathrm{n}}$ & WI & $108.47 \pm 0.8^{\mathrm{u}}$ & WI \\
\hline 43 & $8.23 \pm 1.03^{\mathrm{g}-\mathrm{m}}$ & WI & $87.47 \pm 0.05^{\mathrm{w}}$ & 19.5 \\
\hline 44 & $12.59 \pm 1.7^{\mathrm{d}-\mathrm{f}}$ & WI & $32.29 \pm 0.8^{\mathrm{ab} a c}$ & 19.5 \\
\hline 45 & $10.58 \pm 1.4^{\mathrm{e}-\mathrm{i}}$ & WI & $76.43 \pm 3.5^{\mathrm{x}}$ & 33 \\
\hline 46 & $4.60 \pm 0.6^{1-\mathrm{r}}$ & 3.75 & $412.46 \pm 0.7^{j}$ & WI \\
\hline 47 & $22.75 \pm 0.4^{\mathrm{c}}$ & WI & $278.24 \pm 0.4^{\mathrm{o}}$ & WI \\
\hline 48 & $9.21 \pm 1.5^{\mathrm{e}-\mathrm{j}}$ & WI & $319.60 \pm 0.1^{\mathrm{m}}$ & WI \\
\hline 49 & $15.09 \pm 0.6^{\mathrm{d}}$ & WI & $386.96 \pm 2.8^{1}$ & WI \\
\hline 50 & $25.44 \pm 0.9^{\mathrm{b}-\mathrm{c}}$ & WI & $398.55 \pm 0.8^{\mathrm{k}}$ & WI \\
\hline
\end{tabular}

ND: nondetected. WI: without information. Values represent means \pm standard deviation. Means with different letters per column are statistically different (Tukey, $p \leq 0.05$ ).

out that the increase in the consumption of energy drinks is a public health concern, in particular, in youngsters who commonly mix them with alcohol. There are studies indicating that energy drinks are combined with alcohol [18], which increases the intoxication level in the consumer. Studies in humans suggest that the greatest desire to drink alcohol occurs when it is mixed with energy drinks, which increases the possibility of developing alcohol dependency [19].

3.3. FT-MIR Spectra. The chemical composition of energy drinks can be related to their FT-MIR spectra because the ingredients of energy drinks have characteristic functional 


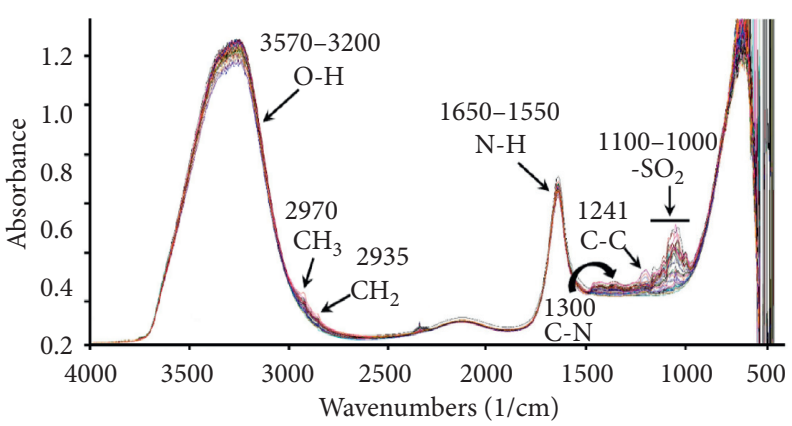

FIGURE 1: FT-MIR spectra of energy drinks.

TABLE 2: Calibration and validation data of the models based on FT-MIR spectroscopy.

\begin{tabular}{|c|c|c|c|c|c|c|c|c|c|c|c|}
\hline \multicolumn{5}{|c|}{ Calibration $(n=40)$} & \multicolumn{7}{|c|}{ Validation $(n=10)$} \\
\hline Algorithm & Parameter & Factors $^{\mathrm{a}}$ & $R c^{2 \mathrm{~b}}$ & $\mathrm{SEC}^{\mathrm{c}}$ & $R v^{2 \mathrm{~d}}$ & $\mathrm{SEP}^{\mathrm{e}}$ & $\mathrm{MD}^{\mathrm{f}}$ & $\mathrm{RR}^{\mathrm{g}}$ & $R E^{\mathrm{h}}$ & $\mathrm{RPD}^{\mathrm{i}}$ & $\% \mathrm{RD}^{\mathrm{j}}$ \\
\hline \multirow{2}{*}{ PCR } & Taurine & 8 & 0.7067 & 6.50 & - & 8.34 & & & & & \\
\hline & Caffeine & 10 & 0.6453 & 198.21 & - & 166.90 & & & & & \\
\hline \multirow{2}{*}{ PLS1 } & Taurine & 5 & 0.9999 & 0.15 & 0.9997 & 0.16 & $0.11-0.54$ & $0.64-1.78$ & $0.74-0.95$ & 14.37 & $1.68-7.29$ \\
\hline & Caffeine & 7 & 0.9999 & 0.26 & 0.9999 & 0.32 & $0.13-0.45$ & $0.87-1.91$ & $0.63-0.81$ & 8.67 & $5.38-8.34$ \\
\hline \multirow{2}{*}{ PLS2 } & Taurine & 20 & 0.9950 & 1.23 & - & 3.11 & & & & & \\
\hline & Caffeine & 20 & 0.9921 & 40.36 & - & 24.14 & & & & & \\
\hline
\end{tabular}

${ }^{\mathrm{a}}$ Factors or latent variables. ${ }^{\mathrm{b}} R c^{2}$ : determination coefficient of calibration, must be as close as possible to $1 .{ }^{\mathrm{c}} \mathrm{SEC}$ : standard error of calibration, must be as low as possible. ${ }^{\mathrm{d}} R v^{2}$ : determination coefficient of validation, must be as close as possible to $1 .{ }^{\mathrm{e}} \mathrm{SEP}$ : standard error of prediction, must be as low as possible. ${ }^{\mathrm{f}} \mathrm{MD}$ : Mahalanobis distance, must be lower than $1 ;{ }^{\mathrm{g}} \mathrm{RR}$ : residual ratio, must be lower than $3 .{ }^{\mathrm{h}} \mathrm{RE}$ : residual error, must be as low as possible. ${ }^{\mathrm{i}} \mathrm{RPD}$ : residual predicted deviation (SD/SEP), must be as high as possible. ${ }^{\mathrm{j}} \% \mathrm{RD}$ : relative difference percentage, must be lower than $10 \%$.

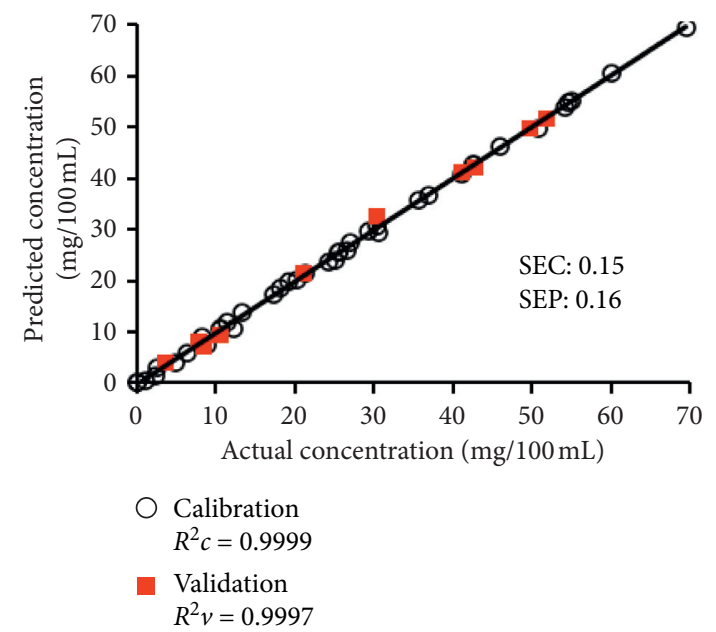

(a)

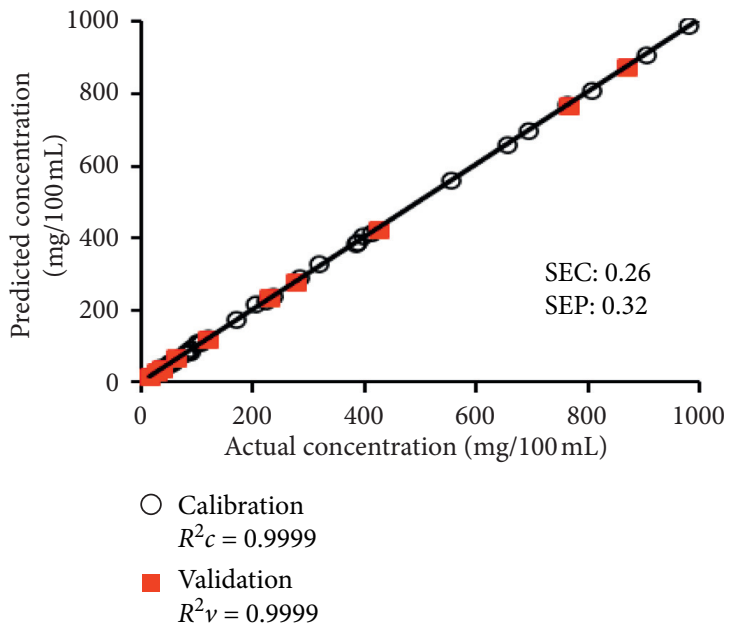

(b)

FIGURE 2: Plots of predicted values versus actual values of (a) taurine and (b) caffeine for the calibration and prediction samples determined by the PLS1 algorithm.

groups that absorb in the FT-MIR spectrum and produce vibrational signals associated mainly with these constituents (Figure 1). The band at $3570-3200 \mathrm{~cm}^{-1}$ is due to stretching vibrations of the $\mathrm{O}-\mathrm{H}$ bond found in molecules such as water. The peak at $2970 \mathrm{~cm}^{-1}$ is related with the stretching vibrational movements of functional group $\mathrm{CH}_{3}$, and the peak at $2935 \mathrm{~cm}^{-1}$ is due to the stretching vibrations of group $\mathrm{CH}_{2}$ [11].
In the region of the fingerprint $\left(1800-900 \mathrm{~cm}^{-1}\right)$, the absorption of the functional groups of taurine and caffeine is observed. At $1650-1550 \mathrm{~cm}^{-1}$, the stretching vibrations of functional group $\mathrm{N}-\mathrm{H}$ of taurine are presented [12]. The most intense bands for caffeine are presented at $1300 \mathrm{~cm}^{-1}$, and they are due to the bending movements of the C-N bond. The small bands at $1241 \mathrm{~cm}^{-1}$ have been assigned to stretching vibrations of the C-C bond of caffeine [20]. 


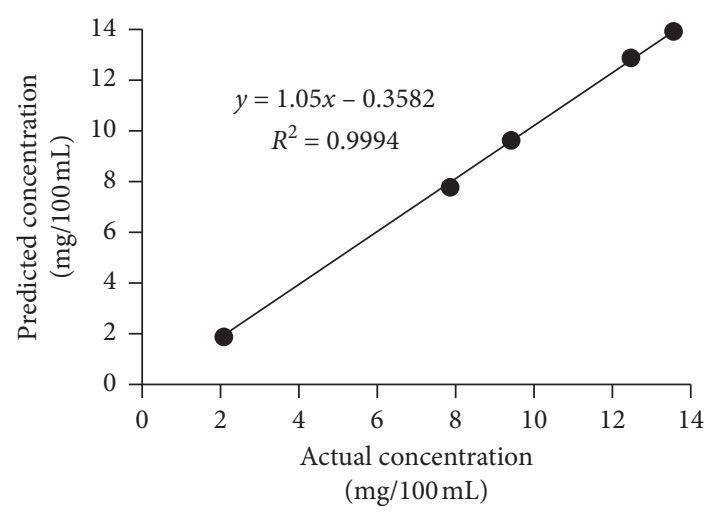

(a)

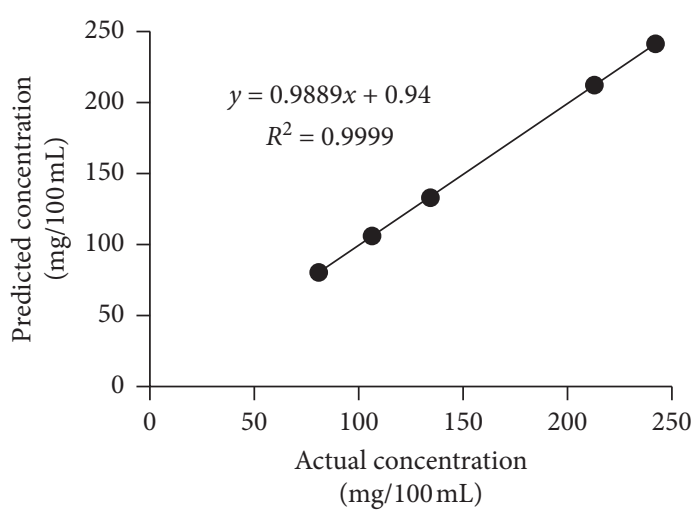

(b)

FIGURE 3: Plots of predicted values versus actual values of (a) taurine and (b) caffeine for the samples used to apply the model developed with PLS1.

Finally, bands at $1100-1000 \mathrm{~cm}^{-1}$ are due to the strong absorption characteristic of the $\mathrm{SO}_{2}$ compound of taurine [12].

3.4. Multivariate Analysis. Models were built in the $1600-950 \mathrm{~cm}^{-1}$ spectral region since this region had the highest correlation of the absorbance of each wavelength number with taurine and caffeine concentrations. The results of the chemometric models are depicted in Table 2. The $R^{2}$ value indicates the correlation of the specified value against the estimated one by the chemometric model. Values of $R^{2}$ higher than 0.9 suggest excellent quantitative information; in contrast, values between 0.81 and 0.66 indicate poorly reliable quantitative predictions [21]. Values of SEC and SEP are the same as the reference value and indicate the regression error; consequently, low values are desirable.

Based on the above, the model with the best adjustment was that developed with PLS1 by obtaining, for the two parameters (taurine and caffeine), $R c^{2}$ values close to 1 (0.9999) and lower SEC values (taurine: 0.15 and caffeine: 0.26 ) and SEP values (taurine: 0.16 and caffeine: 0.32 ) as compared to the models developed with the other algorithms. Likewise, the $R v^{2}$ values were very close to $1\left(R v^{2}\right.$ : 0.9997 and 0.9999 ) for both parameters (Figure 2). Also, latent variables (factors) were 5 and 7 for taurine and caffeine, respectively. Factors represent a significant source of data variations in FT-MIR spectra. Thus, the optimal number of factors is that which provides the lowest SEP.

The validation values that helped define the certainty of the predictions are depicted in Table 2. The Mahalanobis distance (MD) value was lower than 1 (taurine: $0.11-0.54$ and caffeine: $0.13-0.45)$, which indicates that there was similitude between the FT-MIR spectra of the validation samples and the spectra of the calibration set. The Mahalanobis distance is a reliability parameter for the predicted result. The problem samples that are not representative can be identified through the Mahalanobis distance. A distance greater than 1 indicates that the spectral characteristics of the unknown sample are not reflected in the group of standards used in the calibration model. The residual ratio (RR) value was below 3 (taurine: $0.64-1.78$ and caffeine: $0.87-1.91$ ), suggesting that the validated spectrum has characteristics modeled by the number of selected factors. The residual error (RE) value was low (taurine: $0.74-0.95$ and caffeine: $0.63-0.81$ ), which is a measure of the error associated with the calculated property value and represents $95 \%$ confidence limits (two standard deviations). The RE is reported in the same units as the property value. The ratio of performance to deviation (RPD) values ranged from 8.67 to 14.37 ; according to Williams [22], the RPD values between 3.1 and 4.98 are considered acceptable, between 5 and 6.39 are good, and between 6.4 and 8 are very good for analytical purposes. The RPD is a measure of the goodness of fit, and it is defined as the ratio between the standard deviation (SD) of the reference data and the SEP. High values of the RPD are desirable; the higher the RPD, the more accurate the data fitted by the calibration. Finally, the relative difference percentage (\%RD) for all validation samples was lower than 9\%; according to Granato and Ares [23], percentages of $\mathrm{RD} \leq 10 \%$ are considered excellent. These results indicated that the model developed with PLS1 performed an excellent prediction.

After validating the model, it was applied to five energy drinks different from the calibration and validation set. Results (Figure 3) confirmed the accuracy of the model developed with PLS1 since its values were very similar to those obtained with the UV-Vis spectrophotometric method $\left(R^{2} \geq 0.9\right)$; therefore, the values predicted by the model can be considered acceptable.

\section{Conclusions}

The chemometric model developed with PLS1 predicts the taurine and caffeine content of energy drinks simultaneously with certainty. FT-MIR spectroscopy coupled to multivariate analysis yielded similar values to those obtained with conventional analyses, but more economical and faster (measurements can be achieved in $5 \mathrm{~min}$ ), without using solvents or pretreatment of samples, as compared to conventional methods that are time-consuming and require 
considerable amounts of reagents and solvents, considered environmentally damaging. The present method is fast and reliable and may be suitable for routine analysis of energy drinks. The results obtained in this study show that the legislation is necessary to regulate and control the content of taurine and caffeine in energy drinks to avoid adverse health effects. This is because many energy drinks do not provide detailed information on the ingredients or do not indicate the amount in which the main ingredients (taurine and caffeine) are contained. Furthermore, studies must be carried out to develop chemometric models to predict the chemical composition of energy drinks.

\section{Data Availability}

The data used to support the findings of this study are available from the corresponding author upon request.

\section{Conflicts of Interest}

The authors declare that there are no conflicts of interest related to this manuscript.

\section{Acknowledgments}

The authors wish to thank Escuela Nacional de Ciencias Biológicas-Instituto Politécnico Nacional (ENCB-IPN) for the financial support. M.G.-V. wishes to express her gratitude to Consejo Nacional de Ciencia y Tecnología (CONACYT) for the scholarship provided.

\section{References}

[1] A. Anzfa, Formulated Caffeinated Beverages. Inquiry Report, Food Standards Australia New Zealand, Majura Park, Australia, 2001.

[2] European Commission, Opinion on the Scientific Committee on Food on Additional Information on Energy Drinks: Report $E C$, European Commission, Brussel: Belgium, 2003.

[3] NOM-218-SSA1-2011, Norma Oficial Mexicana NOM-127SSA1-1994, Diario Oficial, México, Mexico, 2011.

[4] K. Atanasova and I. Petkova, "Science Publishing Group," International Journal of Food Sciences and Nutrition, vol. 4, no. 1, p. 1, 2015.

[5] B. Vochyánová, F. Opekar, and P. Tuma, "Simultaneous and rapid determination of caffeine and taurine in energy drinks by MEKC in a short capillary with dual contactless conductivity/photometry detection," Electrophoresis, vol. 35, no. 1, p. 1660, 2014.

[6] G. Draganov, I. Pencheva, and K. Todorova, "Taylor and francis online," International Journal of Food Sciences and Nutrition, vol. 3, no. 2, p. 123, 2014.

[7] M. Hohmann, C. Felbinger, N. Christoph, H. Wachter, J. Wiest, and U. Holzgrabe, "Quantification of taurine in energy drinks using 1H NMR," Journal of Pharmaceutical and Biomedical Analysis, vol. 93, no. 1, pp. 156-160, 2014.

[8] B. McConn, "College Journal of Analytical Chemistry," Determination of Taurine in Energy Drinks by High-Performance Liquid Chromatography, vol. 3, no. 1, p. 47, 2012.

[9] M. Ricciutelli, G. Caprioli, M. Cortese et al., "Simultaneous determination of taurine, glucuronolactone and glucuronic acid in energy drinks by ultra high performance liquid chromatography-tandem mass spectrometry (triple quadrupole)," Journal of Chromatography A, vol. 1364, no. 1, pp. 303-307, 2014.

[10] A. Gliszczyńska-Świgło and I. Rybicka, "Simultaneous determination of caffeine and water-soluble vitamins in energy drinks by HPLC with photodiode array and fluorescence detection," Food Analysis Method, vol. 8, no. 1, p. 139, 2014.

[11] B. Ozturk, D. Yucesoy, and B. Ozen, "Application of midinfrared spectroscopy for the measurement of several quality parameters of alcoholic beverages, wine and raki," Food Analysis Method, vol. 5, no. 1, p. 1435, 2012.

[12] S. Triebel, C. Sproll, H. Reusch, R. Goldelmann, and D. Lachenmeier, "Rapid analysis of taurine in energy drinks using amino acid analyzer and Fourier transform infrared (FTIR) spectroscopy as basis for toxicological evaluation," Amino Acids, vol. 33, no. 1, p. 451, 2007.

[13] O. Lau, S. Luk, and T. Chiu, "Spectrophotometric determination of taurine in food samples with phenol and sodium hypochlorite as reagents and an ion-exchange clean-up," Analyst, vol. 115, no. 1, p. 653, 1990.

[14] Jenway, The Quantitative Determination of Caffeine in Beverages and Soft Drinks Using UV Wavelength Spectroscopy. Application Note: A09-010A, Bibby Scientific, England, UK, 2010.

[15] P.E. Spectrum, Quant User's Guide. Version 4.51.02, PerkinElmer, Inc, Massachusetts, MA, USA, 2000.

[16] B. Thomson and S. Jones, MPI Technical Paper No:2013/46, p. 13, Public Health Association, Deakin, Australia, 2013.

[17] Directive 2002/67/EC, "Quinina y productos alimenticios que contiene cafeína,” Diario Oficial, vol. 191, p. 197, 2002.

[18] S. Pettigrew, N. Biagioni, S. C. Jones, J. Stafford, T. Chikritzhs, and M. Daube, "Factors influencing young people's use of alcohol mixed with energy drinks," Appetite, vol. 96, no. 1, pp. 408-415, 2016.

[19] C. A. Marczinski, "Can energy drinks increase the desire for more alcohol?" Advances in Nutrition, vol. 6, no. 1, pp. 96-101, 2015.

[20] S. Armenta, S. Garrigues, and M. Guardia, "Solid-phase FTRaman determination of caffeine in energy drinks," Analytica Chimica Acta, vol. 547, no. 1, p. 197, 2005.

[21] Y. Tamaki and G. Mazza, "Rapid determination of lignin content of straw using fourier transform mid-infrared spectroscopy," Journal of Agricultural and Food Chemistry, vol. 59, no. 2, pp. 504-512, 2011.

[22] P. C. Williams, "Implementation of near-infrared technology," in Near Infrared Technology in the Agricultural and Food Industries, P. C. Williams and K. H. Norris, Eds., pp. 145-169, American Association of Cereal Chemist, St. Paul, MN, USA, 2001.

[23] D. Granato and G. Ares, Mathematical and Statistical Methods in Food Science and Technology, Wiley Blackwell, New York, NY, USA, 2014. 